\title{
Application of Ostrich Antibodies to the Restoration of Hair Growth, a Preliminary and Case Report
}

\author{
Yasuhiro Tsukamoto1 ${ }^{*}$, Barry Hendler ${ }^{2}$, Stuart Greenberg ${ }^{3}$ \\ ${ }^{1}$ Department of Animal Sciences, Graduate School of Environmental \& Biological Sciences, Kyoto Prefecture University, \\ Kyoto, Japan \\ ${ }^{2}$ Microfollicular Hair Transplantation, Ambler, PA, USA \\ ${ }^{3}$ Clinical Studies, OstriGen Holdings, West Newton, MA, USA \\ Email: *ytsuka@kpu.ac.jp
}

How to cite this paper: Tsukamoto, Y., Hendler, B. and Greenberg, S. (2018) Application of Ostrich Antibodies to the Restoration of Hair Growth, a Preliminary and Case Report. Journal of Cosmetics, Dermatological Sciences and Applications, 8, 179-184.

https://doi.org/10.4236/jcdsa.2018.84019

Received: October 6, 2018

Accepted: October 19, 2018

Published: October 22, 2018

Copyright $\odot 2018$ by authors and Scientific Research Publishing Inc. This work is licensed under the Creative Commons Attribution International License (CC BY 4.0).

http://creativecommons.org/licenses/by/4.0/

\section{cc) (i) Open Access}

\begin{abstract}
The hormone dihydrotestosterone (DHT) and the catalyst $5 \alpha$-reductase play very important roles in the hair loss due to androgenetic alopecia (AGA). Recently, some chemicals against these hormones have been commercialized as therapeutics for AGA. In the present study, we have attempted to find out the potential effects of antibodies on AGA therapeutics as an inhibitor of androgenic hormones. The immune system of the ostrich is believed to be the most versatile and powerful of any animal on the planet, and antibodies derived from the ostrich egg yolk are now being developed for a wide range of diseases and ailments. Ostrich antibodies against DHT and $5 \alpha$-reductase have been produced and combined with antibodies against harmful skin bacteria to restore normal hair growth in AGA cases. Preliminary testing with six volunteer subjects showed that ostrich antibodies were clearly quite effective in hair regrowth.
\end{abstract}

\section{Keywords}

Alopecia, AGA, Ostrich, Antibody

\section{Introduction}

The involvement of the hormone dihydrotestosterone (DHT) and the catalyst $5 \alpha$-reductase in the male pattern baldness of androgenic alopecia (AGA) is well known [1] [2] [3]. Reduction of DHT synthesis has been shown to promote restoration of hair growth in AGA [4].

Birds are a superior source of antibodies. An avian form of antibodies, called 
immunoglobulin Y ("IgY"), is passed by the female into the yolk of her eggs. The avian IgY are relatively easy and inexpensive to extract and purify from the egg yolk.A wide range of immunotherapy research has been performed using IgY, primarily derived from chicken eggs [5] [6] [7] [8] [9]. The administration of IgY has been tested on some microbes [10]. In the previous studies, we have found that ostriches (Struthio camelus) are a remarkably valuable source of IgY [11] [12] [13] [14]. They are a very old species, and the ostrich immune system has adapted to become the best of any animal. An ostrich can produce antibodies within two weeks of its exposure to an antigen, and its IgY is also less heat sensitive and more acid resistant than other avian IgY. Perhaps the greatest advantage for ostrich IgY is the ability of the ostrich to produce large volumes at low cost. A single ostrich egg contains about 4 grams of IgY, and an ostrich hen will produce approximately 100 eggs per year over a 55 years lifetime. Serious early examples of the usefulness of ostrich IgY are in antibodies to avian and seasonal influenzas and corona viruses [11] [12] [15]. Also, ostrich IgY against dermal bacteria and pollen allergens have been incorporated in cosmetic products for skin care [14] [16].

The idea of using ostriches to produce antibodies against DHT and $5 \alpha$-reductase has emerged from the experience of using these antibodies against a wide range of diseases and ailments, including Influenza viruses, tumor markers, food poisoning pathogens, dermal bacteria and allergens. Its low cost and its ready availability in large quantities make ostrich IgY an interesting candidate for neutralizing DHT and $5 \alpha$-reductase to promote hair growth in cases of AGA. In the present study, we wish to show the application of ostrich IgY to the restoration of hair growth in AGA.

\section{Materials \& Methods}

\subsection{Production of Antibodies to DHT and $5 \alpha$-Reductase}

Laying hen ostriches were immunized with DHT (50 ug/bird) and $5 \alpha$-reductase (50 ug/bird) asantigens. The ostrich eggs were collected, and the yolk was separated from the albumin at 4 weeks post initial immunization according to our methods [11]. Then An enzyme-linked immunosorbant assay (ELISA) using ostrich IgY were performed to confirmed the IgY had high reactivity to the antigens. Each well of a polystyrene ELISA plate (Sumitomo Bakelite, Japan) was coated with $0.2 \mu \mathrm{gDHT}$ or $0.2 \mu \mathrm{g} 5 \alpha$-reductase antigens in phosphate-buffered saline (PBS), and the plate was incubated overnight at $4^{\circ} \mathrm{C}$. Each of the following incubation steps were preceded by washing the wells twice with PBS containing $0.05 \%$ Tween 20 . The wells were blocked for nonspecific binding by the addition of a commercial blocking buffer (DS Pharma Biomedical, Suita, Japan) and incubated at $37^{\circ} \mathrm{C}$ for $2 \mathrm{~h}$. The serial dilutions of purified IgY were added vertically to the wells, and the plates were incubated at $37^{\circ} \mathrm{C}$ for $1 \mathrm{~h}$. HRP-conjugated rabbit IgG against ostrich IgY diluted (1:5000) in PBS was dispensed into each well. The plate was incubated for $1 \mathrm{~h}$ at $37^{\circ} \mathrm{C}$. A substrate buffer containing TMB 
(Sumitomo Bakelite, Japan) was then added to each well, and the plates were incubated at $37^{\circ} \mathrm{C}$ for $15 \mathrm{~min}$. The reaction was terminated by the addition of a stopping reagent (1.25 M sulfuric acid). The absorbance was recorded at $450 \mathrm{~nm}$ using an ELISA plate reader (DS Pharma Biomedical). ELISA titer was recorded as highest dilutions showing over twice absorbance of preimmune IgY.

As a result of the stability test, Exoderm ${ }^{1}$, a commercial hair conditioner in which the binding activity of IgY was highly stable, was selected as a base material. A cocktail of IgY against DHT, $5 \alpha$-reductase, Staphylococcus aureus, and Propionibacterium acnes [16] was mixed into the base material and used as a test sample for AGA study volunteers.

\subsection{Description of Initial Study}

A study was designed to evaluate the effectiveness of the antibody mixture in stimulating the regrowth of hair. The objective was to make a qualitative visual assessment of increased hair growth in the case of six individuals with varying degrees of male pattern baldness: the clinical trials were performed in six AGA volunteers who received approval from informed consent of dermatologist in dermatology clinics in Philadelphia, USA (Table 1).

A higher proportion of older subjects was chosen, because it was believed that they would have more difficulty re-growing hair. The subjects were instructed to use the material daily for three months. After washing their hair, they were to apply the material, and let it stay on for ten minutes before washing again. Photos were taken prior to start of the study, and then after three months.

\section{Results and Qualitative Feedback from Study Subjects}

A high volume of IgY was then purified using proprietary methods and confirmed to have high reactivity to the antigens by ELISA: approximately $4 \mathrm{~g}$ of $\operatorname{IgY}$ was collected from each egg yolk and an ELISA titer over 56,000 on each antigen was recorded. In this manner, we were able to generate a high volume of high quality ostrich IgY against DHT and $5 \alpha$-reductase. A stability test showed that the binding activity of the ostrich IgY was found to be maintained at a high rate (ELISA titer was over 14,000) in the basement material at room temperature for at least 2 years.

Table 1. Brief information on the study subjects.

\begin{tabular}{cccc}
\hline Subject & Age (years) & Extent of Baldness & Prior Treatment \\
\hline A & 74 & Norwood Type VI & 4 Hair Transplantations \\
B & 40 & Norwood Type III Vertex & None \\
C & 75 & Norwood Type VI & Hair Transplantation \\
D & 67 & Norwood Type III & None \\
E & 68 & Norwood Type V A & None \\
F & 74 & Norwood Type VI & 3 Hair Transplantations \\
\hline
\end{tabular}

${ }^{1}$ Bentlin Products LLC, P.O. Box 183, Basking Ridge, NJ 07920 USA. 
All subjects demonstrated hair regrowth. Photos at the start and at three months are presented for each of the subjects (Figures 1-6). The subjects were pleased with the results. The degree of satisfaction was, not surprisingly, proportional to the subjects' perception of hair growth. However, the subjects were unanimously displeased with use of the base material. They found it difficult to use as part of this regimen. They did not like the complexity of the regimenwashing before application, and then washing again afterwards.

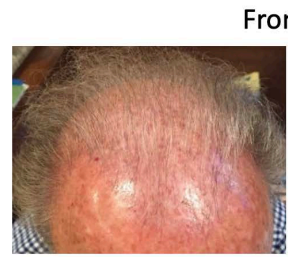

Start rontal

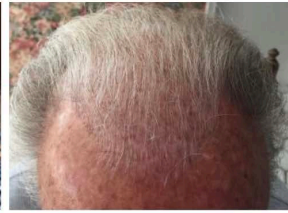

3 months

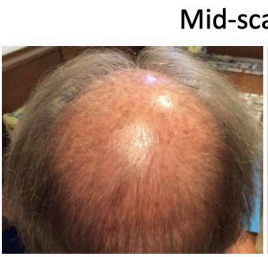

Start
id-scalp/Vertex

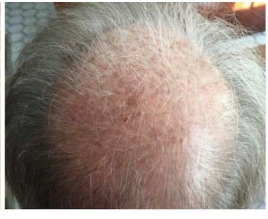

3 months

Figure 1. Subject "A" (74 years old, Norwood Type VI), Frontal and Mid-scalp/Vertex.

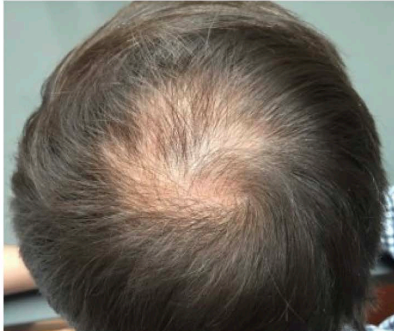

Start

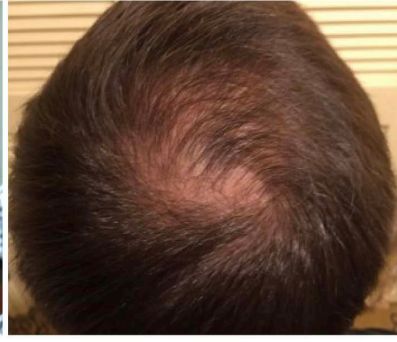

2 months

Figure 2. Subject “B” (40 years old, Norwood Type III Vertex), Vertex.

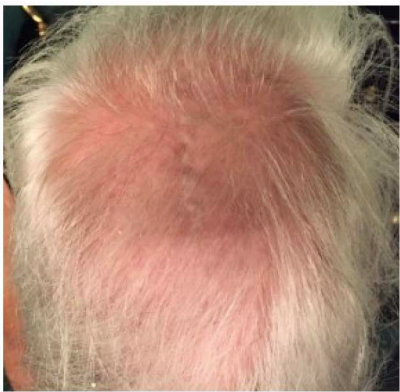

Start

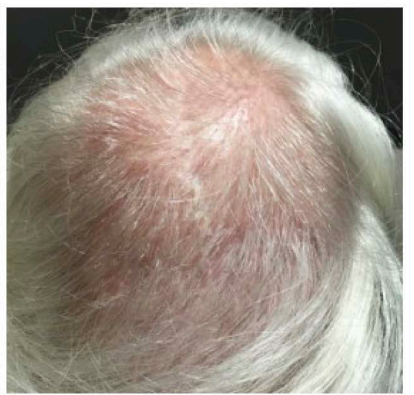

3 months

Figure 3. Subject "C" (75 years old, Norwood Type VI), Mid-scalp/Vertex.

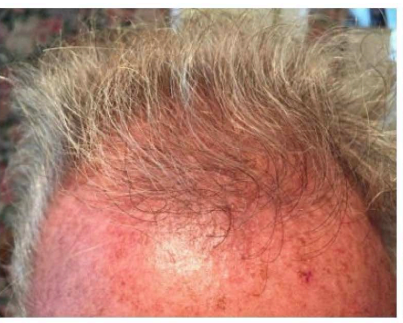

Start

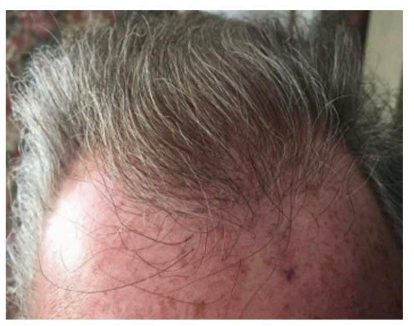

3 months

Figure 4. Subject "D” (67 years old, Norwood Type III), Frontal. 


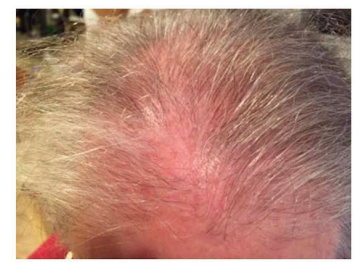

Start

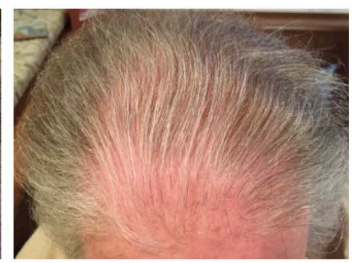

3 months

Figure 5. Subject "E" (68 years old, Norwood Type $V A$ ), Frontal/Mid-scalp.

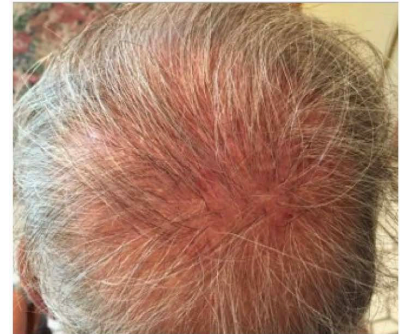

Start

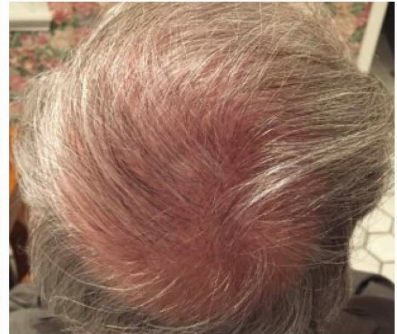

3 months

Figure 6. Subject "F" (74 years old, Norwood Type VI), Vertex.

\section{Discussion}

In the present study, we have focused on the neutralization of DHT and $5 \alpha$-reductase by using ostrich antibodies with the purpose of re-growing hair in the case of AGA. Antibodies against harmful skin bacteria were added to normalize the dermal flora [14] [16]. This combination of ostrich antibodies is clearly quite effective in hair regrowth.

The dissatisfaction with the base material and its usage regimen suggests the need for a new, more convenient-to-use base material. Because of the positive results of this initial study, a larger study, randomized double-blind testing, with a broader range of subjects and a variation in regimen, is a logical next step. It will be particularly interesting to include women in the next study.

\section{Acknowledgements}

We thank Dr. Kazuhide Adachi, Mrs. Hatsuki Matsunaga and Miss Saaya Ueno at Kyoto Prefecture University for their technical supports.

\section{Conflicts of Interest}

The authors declare that there is no conflict of interest that could be perceived as prejudicing the impartiality of the research reported.

\section{References}

[1] Sawaya, M.E. and Price, V.H. (1997) Different Levels of 5alpha-Reductase Type I and II, Aromatase, and Androgen Receptor in Hair Follicles of Women and Men with Androgenetic Alopecia. Journal of Investigative Dermatology, 109, 296-300. https://doi.org/10.1111/1523-1747.ep12335779

[2] Schweikert, H.U. and Wilson, J.D. (1974) Regulation of Human Hair Growth by Ste- 
roid Hormones. I. Testerone Metabolism in Isolated Hairs. The Journal of Clinical Endocrinology \& Metabolism, 38, 811-819. https://doi.org/10.1210/jcem-38-5-811

[3] Dallob, A.L., Sadick, N.S., Unger, W., et al. (1994) The Effect of Finasteride, a 5 Alpha-Reductase Inhibitor, on Scalp Skin Testosterone and Dihydrotestosterone Concentrations in Patients with Male Pattern Baldness. The Journal of Clinical Endocrinology \& Metabolism, 79, 703-706.

[4] Kaufman, K.D., Olsen, E.A., Whiting, D., et al. (1998) Finasteride in the Treatment of Men with Androgenetic Alopecia. Finasteride Male Pattern Hair Loss Study Group. Journal of the American Academy of Dermatology, 39, 578-589. https://doi.org/10.1016/S0190-9622(98)70007-6

[5] Schade, R., Pfister, C., Halatsch, R. and Henklein, P. (1991) Polyclonal IgY Antibodies from Chicken Egg Yolk. An Alternative to the Production of Mammalian IgG Type Antibodies in Rabbits. ATLA, 19, 403-419.

[6] Schade, R., Schniering, A. and Hlinak, A. (1992) Polyclonal Avian Antibodies Extracted from Egg Yolk as an Alternative to the Production of Antibodies in Mammals-A Review. ALTEX, 9, 43-56.

[7] Larsson, A., Balow, R.M., Lindahl, T.L. and Forsberg, P.O. (1993) Chicken Antibodies: Taking Advantage of Evolution-A Review. Poultry Science, 72, 1807-1812. https://doi.org/10.3382/ps.0721807

[8] Gross, M. and Speck, J. (1996) Avian Yolk Antibodies in Diagnosis and Research. Dtsch Tierarztl Wochenschr, 103, 417-422.

[9] Zhang, X., Calvert, R.A., Sutton, B.J. and Doré, K.A. (2017) IgY: A Key Isotype in Antibody Evolution. Biological Reviews of the Cambridge Philosophical Society, 92, 2144-2156. https://doi.org/10.1111/brv.12325

[10] Thu, H.M., Myat, T.W., Win, M.M., Thant, K.Z., Rahman, S., Umeda, K., Nguyen, S.V., Icatlo Jr., F.C., Higo-Moriguchi, K., Taniguchi, K., Tsuji, T., Oguma, K., Kim, S.J., Bae, H.S. and Choi, H.J. (2017) Chicken Egg Yolk Antibodies (IgY) for Prophylaxis and Treatment of Rotavirus Diarrhea in Human and Animal Neonates: A Concise Review. Korean Journal for Food Science of Animal Resources, 37, 1-9. https://doi.org/10.5851/kosfa.2017.37.1.1

[11] Adachi, K., Handharvani, E., Sari, D.K., Takama, K., Fukuda, K., Endo, I., Yamamoto, R., Sawa, M., Tanaka, M., Konishi, I. and Tsukamoto, Y. (2008) Development of Neutralization Antibodies against Highly Pathogenic H5N1 Avian Influenza Virus Using Ostrich (Struthio camelus) Yolk. Molecular Medicine Reports, 1, 203-209.

[12] Kamiyama, Y., Adachi, K., Handharyani, E., Soejoedono, R.D., Kusano, T., Inai, M., Tsukamoto, M., Kashiwagi, S. and Tsukamoto, Y. (2011) Protection from Avian Influenza H5N1 Virus Infection with Antibody-Impregnated Filters. Virology Journal, 8, 54. https://doi.org/10.1186/1743-422X-8-54

[13] Tsukamoto, M., Hiroi, S., Adachi, K., Kato, H., Inai, M., Konishi, I., Tanaka, M., Yamamoto, R., Sawa, M., Handharvani, E. and Tsukamoto, Y. (2011) Antibodies against Swine Influenza Virus Neutralize the Pandemic Influenza Virus A H1N1. Molecular Medicine Reports, 4,209-214. https://doi.org/10.3892/mmr.2011.410

[14] Tsukamoto, Y., Nishiura, K. and Maeda, O. (2013) Development of Functional Skin-Care Products Using Ostrich Antibodies. Fragance Journal, 6, 36-41.

[15] Tsukamoto, Y., Nakano, Y. and Adachi, K. (2018) Protection against Infectious Bronchitis Virus, a Corona Virus Infection, Using Ostrich Antibodies. Health, 10, 1294-1308. https://doi.org/10.4236/health.2018.1010100

[16] Tsukamoto, Y., Maeda, O., Shigekawa, G., Greenberg, S. and Hendler, B. (2018) Ostrich Antibody and Its Application to Skin Diseases, a Review and Case Report. Health, 10, in Press. 